\title{
Human-modified temperatures induce species changes: Joint attribution
}

\author{
Terry L. Root*, Dena P MacMynowski, Michael D. Mastrandrea, and Stephen H. Schneider \\ Center for Environmental Science and Policy, Stanford Institute for International Studies, Stanford University, Stanford, CA 94305-6055
}

Contributed by Stephen H. Schneider, March 30, 2005

\begin{abstract}
Average global surface-air temperature is increasing. Contention exists over relative contributions by natural and anthropogenic forcings. Ecological studies attribute plant and animal changes to observed warming. Until now, temperature-species connections have not been statistically attributed directly to anthropogenic climatic change. Using modeled climatic variables and observed species data, which are independent of thermometer records and paleoclimatic proxies, we demonstrate statistically significant "joint attribution," a two-step linkage: human activities contribute significantly to temperature changes and human-changed temperatures are associated with discernible changes in plant and animal traits. Additionally, our analyses provide independent testing of grid-box-scale temperature projections from a general circulation model (HadCM3).
\end{abstract}

climate change | double attribution | global warming | plant animal impacts | regional climate change

$\mathbf{T}$ he Third Assessment Report of the Intergovernmental Panel on Climate Change (IPCC) Working Group I concluded that humans are changing the climate by injecting greenhouse gases and aerosols into the atmosphere (1). One line of evidence that was examined included temperature trends produced by the HadCM3 general circulation model (GCM) in response to three different scenarios: $(i)$ only natural climatic forcings (hereafter called NF), (ii) only greenhouse gas and aerosol forcings (anthropogenic forcings, AF), and (iii) a coupling of both natural and anthropogenic forcings (combined forcings, CF). Stott and colleagues (2) compared surface-air temperature data from all three model runs to observed global surface-air temperatures. Results for the CF yield the closest match with observed temperatures over the 20th century, AF produce a good fit, but NF results are notably less skillful. Stott (3) has extended these methods to a regional analysis that yields similar results, further confirming the importance of $\mathrm{AF}$ for credible simulation of historical observed temperatures.

Even though paleoclimatic proxies, surface thermometers, satellites, and weather balloons are recording global warming, interpretations of these instrumental records have sometimes been contentious $(4,5)$. Having measures of warming that are not based on the interpretations of these data allows independent testing of different external and internal factors influencing the climate. For instance, results from biological metaanalyses, which examined numerous studies to determine the occurrence of a biotic signal consistent with climatic change, indicated that “... a significant impact of recent climatic warming is discernible in the form of long-term, large-scale alterations of animal and plant populations" (ref. 6, p. 59$)$. The vast majority $(\approx 80 \%)$ of species exhibiting changes are shifting in the manner expected with increasing temperature (6). What has been lacking thus far, however, is statistical evidence that attributes a significant portion of the changes seen in plants and animals (6-8) directly to human-caused increases in global temperature in the same manner that earlier detection and attribution studies have related $\mathrm{AF}$ and observed temperature changes $(1,2)$. Our study associates plant and animal responses to particular climatic forcings (NF, AF, or $\mathrm{CF}$ ) and demonstrates a strong linkage between biotic trends and anthropogenic climatic change.

We compare changes in species phenological traits, such as shifts in the time of blooming, to modeled temperature data generated by the HadCM3 GCM (9) at the scales of both one grid box ("local scale") and the average of nine grid boxes ("more regional scale"). We expect that, at local and/or more regional scales, the temporal changes in phenology of species around the globe are much more weakly associated with temperatures driven by NF than temperatures driven by either AF or a mixture of $\mathrm{NF}$ and $\mathrm{AF}$. Remembering that the global-level modeled temperatures using coupled NF and AF provide the highest association with measured temperature trends (3), we expect the associations between species and modeled temperatures when using either of the two forcings alone will be weaker than those when $\mathrm{CF}$ are used, unless one of the forcings (i.e., NF or $\mathrm{AF}$ ) dominates the signal in the $\mathrm{CF}$ case.

Our null hypothesis is that there is no statistically significant difference in the associations between species and temperatures modeled with NF, AF, or CF. To test this hypothesis, we examine the relationships between phenological changes exhibited in actual plant and animal data, and HadCM3-GCM-modeled temperature data derived by using three different forcings: NF, $\mathrm{AF}$, and a mixture of these two. Our results indicate that modeled-temperature values derived assuming only NF typically do not track species changes as well as those derived using only $\mathrm{AF}$ or $\mathrm{CF}$. These results consistently provide strong evidence for the case of "joint attribution" (also known as double attribution): (i) human activities involving injection of greenhouse gases and aerosols into the atmosphere can be attributed by modeling studies to be changing the surface-air temperatures at a local and more regional scale, and (ii) some phenological changes in species at various locations around the planet are highly likely to be attributed to this human-induced temperature increase.

The IPCC Third Assessment Report (1) suggests that GCMmodeled temperatures at the subcontinental scale $\left(\approx 10^{7} \mathrm{~km}^{2}\right)$ and above are dominated by general circulation processes that are fairly well represented in models, whereas the accuracy of model simulations below this level is expected to decrease with spatial scale as more local processes that are not as well represented in the models become more significant (10). In our joint-attribution analyses, the explanatory power of GCMmodeled temperatures is no worse at the one-grid-box than at the nine-grid-box scale. Explanations for this result could well involve characteristics of the spatiotemporal scales at which species respond to temperature trends. Further investigation of possible mechanisms that influence the multiscalar associations of species with climate is obviously needed but is beyond the scope of this analysis.

In addition to demonstrating model skill, our results based on plant and animal observations (in effect, temperature proxies)

Abbreviations: $A F$, anthropogenic forcings; $C F$, combined forcings; $G C M$, general circulation model; IPCC, Intergovernmental Panel on Climate Change; NF, natural climatic forcings.

*To whom correspondence should be addressed. E-mail: troot@stanford.edu.

C 2005 by The National Academy of Sciences of the USA 
provide an independent, unique attribution method that is unaffected by standard, and at times contentious, methodological issues, such as the extent to which thermometer data are biased due to heat-island effects (11), or whether the orbital degradations of satellites are properly taken into account (12). We certainly do not assert that plant-and-animal-climate-proxy data should substitute for archives of actual instrumental climatic records or the detection and attribution literature built upon them. However, use of these species data from varied locations and diverse taxa can provide an independent confirmation of the many previous attribution studies using instrumental observations (e.g., ref. 4 and references therein). Moreover, finding significant correlations between biological records and HadCM3-GCM-modeled anthropogenic climatic changes increases confidence in the ecological implications of GCM-based projections of climatic changes in the 21st Century $(6,8,13,14)$.

\section{Methods}

Temperature Data. From historical model runs of the HadCM3 GCM (an ensemble of four averaged runs for each forcing), we obtained temperature data corresponding to the season and specific years of a species' observation for each model grid box containing the study site of one or more species. The spring season in the Northern Hemisphere was defined as the mean of March, April, and May temperatures; in the Southern Hemisphere, the months of September, October, and November were averaged. To determine whether differences exist between a local and more regional scale, we examined data from $(i)$ the $2.5^{\circ}$ $\times 3.75^{\circ}$ grid box containing each species study site and $(i i)$ the nine grid boxes covering and surrounding each site (area centered on the grid box covering the study site). Grid boxes over large bodies of water were excluded in the regional-scale analysis.

Species Data. Our intent was to determine whether a signal of human-induced global warming can be identified in the changing phenology of wild plants and animals. We obtained data on species that exhibit a statistically significant trend $(P<0.10)$ in a phenological trait (e.g., timing of blooming or timing of migration). Thus, for these species, our results indicate whether GCM-modeled temperatures that include AF better explain the pattern of those changes than comparable temperature simulations without AF climatic forcings. By only analyzing species that have demonstrated temperature-associated phenological changes, our results are not representative of the climatic change sensitivity of all species. Instead, we were able to $(i)$ detect a global biotic signal of temperature-associated species changes (see also refs. 6 and 8 ) and (ii) determine whether that signal can be directly attributed to human greenhouse gas emissions.

The temporal scale covered by the various studies range from 11 to 97 years, having a mean of 28 years. We used data from 29 published studies (15-43) and one author's (T.L.R.) unpublished data. These data are distributed over 41 GCM grid boxes and include 145 species representing a variety of taxa (e.g., forbs, trees, invertebrates, and birds). Species were observed at 26 sites in Europe, 9 in North America, and 7 in Asia. A majority of locations $(62 \%)$ occur in Europe, and most species were recorded in North America (57\%).

Analyses. We used species data in association with GCMmodeled temperature values at both one-grid-box and nine-gridbox scales to test for joint attribution in three different ways. First, we focused on 130 Northern Hemisphere species exhibiting statistically significant changes $(P<0.10)$ in spring phenology. To facilitate comparisons among taxa and regions, we divided these species into seven overlapping groups, each of which contains at least 25 species: all species $(n=130)$, species north of $45^{\circ}$ latitude $(n=52)$, North American species $(n=76)$, European species $(n=44)$, birds $(n=40)$, herbaceous plants $(n=60)$, and woody plants $(n=25)$.

Phenological changes were measured consistently in all studies (date of event), allowing us to calculate the mean annual phenological change for sets of species in the Northern Hemisphere from 1969 to 1999 (Fig. 1A). Each species is not recorded each year, but the calculation of the annual mean includes a minimum of $50 \%$ of the species in the total sample. Using a Pearson correlation, we quantified the association between the annual phenological averages and each of the three time series of GCM-temperature data (i.e., temperatures modeled with NF, $\mathrm{AF}$, and $\mathrm{CF}$ ) at three spatial scales: $(i)$ averaging only grid boxes covering study locations, (ii) averaging all grid boxes in the Northern Hemisphere (ocean and terrestrial), and (iii) grid boxes around the entire planet (ocean and terrestrial).

The second way that we tested for joint attribution was by calculating the individual correlation coefficients between the three temperature time series and species' data for each of the 145 species and then calculating the means of the correlation coefficients for species included in each of the regional and taxa-specific subsets described above. To assess possible bias due to multiple-species observations being recorded at one location, we used Monte Carlo simulations with one species chosen randomly from each of the 41 individual grid boxes containing the 42 site locations. A total of 5,000 iterations were run. From these runs, we determined average correlation coefficients between the species' data and temperature time series for each of the three HadCM3 temperature simulations. Specifically, 14 different comparisons were examined: local and more-regional analyses for all species together and for the six different subsets of species.

Our third test for joint attribution included all species showing a statistically significant phenological change. For this test, we examined the frequency distribution of the species' correlation coefficients as calculated between the phenological change of individual species and each of the three different types of modeled temperature data at each location.

Caveats and Perspective. The strength (magnitude) of the correlation coefficients between species data and modeled temperature data are not expected to be particularly high for several reasons. First, unpredictable factors (e.g., chaotic weather fluctuations) introduce a significant element of stochasticity in reality and in climatic models. Second, missing factors (e.g., land-use changes) or other sources of uncertainty exist in each of the various climatic forcing factors, which means that the forcings that drive HadCM3 GCM results cannot fully reflect all influences. Third, unavoidable approximations inherent in the model structure introduce errors into GCMs, especially at grid-box levels $(44,45)$. Fourth, causes of change in species' phenological traits are complex, multifactorial, and only partially understood (46). Fifth, observations of species traits are not error-free. Sixth, both climatic and species trends are just becoming discernible from background levels. All of these factors generate variability.

Our investigation focused on determining whether a statistically clear signal emerges despite these uncertainties. Even if an obvious statistical association between species changes and anthropogenically forced GCM-modeled temperatures is found, supporting a claim for joint attribution, a nonzero but highly unlikely possibility exists that gross underestimates in NF assumptions in HadCM3 coincident with gross overestimates in $\mathrm{AF}$ produce fortuitous correlations. Indeed, our claims for joint attribution rest upon the assumption that the "conventional wisdom" embodied in the NF and AF used in GCM runs are sufficiently accurate, a highly likely assumption because it is built on a generation of assessments of NF and AF processes (1). 

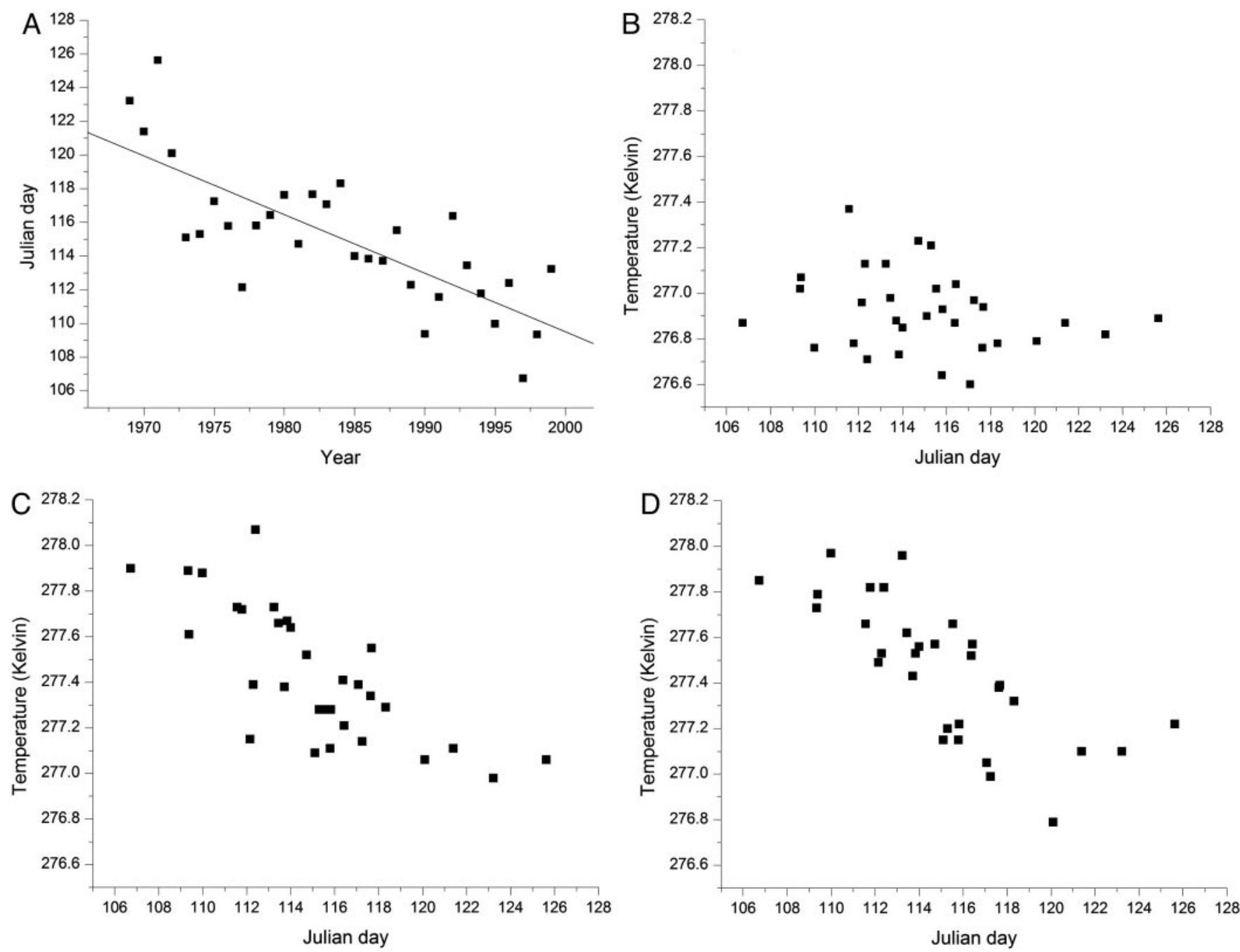

Fig. 1. For each year, the occurrence dates (Julian) of spring phenological traits are averaged over all Northern Hemisphere species exhibiting statistically significant changes in those traits $(n=130)$. These averages are plotted against the following. (A) Year with a -3.2 day change per decade. $(B)$ The average modeled spring (March, April, and May) temperatures including only natural forcings at each study location $(r=0.22, P<0.23)$. (C) Identical to $B$ but including only anthropogenic forcings $(r=-0.71, P<0.001)$. (D) Identical to $B$ but including both natural and anthropogenic forcings $(r=-0.72, P \leq 0.001)$.

Thus, assigning confidence to our conclusions is primarily an exercise in assessing the likelihood that the $\mathrm{NF}$ and $\mathrm{AF}$ used to drive the HADCM3 model were reasonable. Our personal understanding of this literature is that a high confidence can be assigned to our results, although that is of necessity a subjective assessment (47).

\section{Results and Discussion}

Species Trends Over Time. We examine 130 species showing statistically significant phenological shifts $(P<0.10)$ during spring in the Northern Hemisphere as a group and for the six taxa/region subsets described above. The expected direction of change is negative (shift earlier in the season) in response to warming. The average number of days changed is -3.2 days/ decade for all 130 species $(P<0.001),-4.4$ days/decade for species north of $45^{\circ}$ latitude $(P<0.001),-2.0$ days/decade for North American species $(P<0.05),-5.0$ days/decade for European species $(P<0.001),-5.1$ days $/$ decade for birds $(P<$ $0.001),-2.1$ days/decade for herbaceous plants $(P<0.01)$, and -5.2 days/decade for woody plants $(P<0.05)$. As expected, the group of species at the highest latitudes exhibits a much stronger phenological shift ( -4.4 days/decade) than Northern Hemi- sphere species south of $45^{\circ}(n=78,-1.2$ days/decade, $P<0.23)$. These results are consistent with other studies $(6,8)$.

Local, Hemispheric, and Global Scales. If species are indeed acting as surrogate and independent "springtime thermometers," and our hypothesis addressing joint attribution is correct, then the association between the annual averaged phenological data for all species should be highest with the CF GCM-modeled temperature data. Because of extensive aggregation of both the climatic and biotic data, the correlation coefficients between the phenological averages and temperatures modeled at both the Northern Hemisphere scale and the entire globe are expected to be stronger than the correlation coefficients at the (noisier) grid-box scale. For phenological averages of all species, values of the correlations with modeled temperature assuming NF, AF, and CF, respectively, are, for grid boxes, $-0.08(P \leq 0.70),-0.40$ $(P \leq 0.03)$, and $-0.51(P \leq 0.005)$; for the Northern Hemisphere, $-0.22(P \leq 0.23),-0.71(P \leq 0.001)$, and $-0.72(P \leq 0.001)$ (Fig. $1 B-D)$; and, for the globe, $-0.15(P \leq 0.45),-0.66(P \leq 0.001)$, and $-0.77(P \leq 0.001)$. Correlations for the six subsets of species exhibit a strikingly similar pattern. Associations between species data and temperatures modeled by using $\mathrm{CF}$ are strongest in all cases. 
Another way to represent the previous results is to examine the amount of variability explained $\left(r^{2}\right)$ in species data by modeled anthropogenic temperature data at the scales of grid boxes, the Northern Hemisphere, and the globe. These values are 16\%, $50 \%$, and $44 \%$, respectively. Variability in species' trends explained by temperatures modeled using NF is low at all three scales: $<1.0 \%, 4.8 \%$, and $2.3 \%$, respectively. Combined forcings consistently explained the most variability: $26 \%, 52 \%$, and $59 \%$, respectively. The magnitudes of the correlations and the percentage of explained variability provide exceptionally strong support for joint attribution. Given the low percentage of variability explained by the NF and the high percentage for $\mathrm{CF}$, we conclude that a substantial fraction of temporal changes in species across the Northern Hemisphere can be directly attributed to human influences on climate as modeled by the HadCM3 GCM.

Magnitudes of Correlation Coefficients. For the seven groups of species at both the local and more regional scales, the means of the correlation coefficients between the species' data and temperatures modeled with $\mathrm{CF}$ are significantly higher than the means between species' data and temperatures modeled with either of the other two forcings $(P<0.05)$. For all 145 phenologically changing species, the mean values are $-0.27(\mathrm{CF})$, -0.08 (AF), and $0.01(\mathrm{NF})$ at single-grid scale and $-0.26(\mathrm{CF})$, $-0.07(\mathrm{AF})$, and $0.01(\mathrm{NF})$ for the nine-grid scale. The values for the two scales are not statistically different from each other. All subsets yield similar results, and again, no statistical differences exist between the two scales. Because AF are a component of $\mathrm{CF}$, AF clearly contribute toward shaping these associations. Despite many uncertainties in each component of our analyses (see above), a consistent conclusion emerges: All 14 cases (all 145 species and six subgroups of species for both grid scales) support joint attribution. Furthermore, 133 of the 145 species $(92 \%)$ are shifting in the direction (earlier) expected by global warming.

For 7 of the 14 cases (both scales for all species combined, North America, and birds, and regionally for herbaceous plants), the means of the correlation coefficients between species' data and temperatures modeled with human forcings are greater than the means of the correlation coefficients between species' data and temperatures modeled with NF $(P<0.05)$. This suggests that, compared with NF, AF are more important in driving temporal changes in species. Again, these results provide strong evidence for joint attribution, as well as suggesting the discernible skill of this GCM in simulating recent climatic trends, even at local and more regional scales. For the other seven cases (both scales for northern latitudes, Europe, and woody plants, and locally for herbaceous plants), the means of the correlation coefficients between species data and naturally and anthropogenically forced temperatures are not statistically different from each other, but both are statistically significantly lower in magnitude than the mean of the correlation coefficients between species data and temperatures modeled with $\mathrm{CF}$.

Our correlation results are strikingly similar at both local and more regional scales. Our scales of analysis (local and more regional) roughly fall within the definition of "regional scale" presented by the IPCC $\left(10^{4} \mathrm{~km}^{2}\right.$ to $\left.10^{7} \mathrm{~km}^{2}\right)$. As discussed above, model-generated data at these scales are not usually considered as reliable as more aggregated data (10). Nevertheless, our results suggest that the grid-box-scale data have no less explanatory power than the more regional temperature data, at least in their association with species data. Karoly (personal communication) has also found that regional-scale data modeled with the GCM have as much explanatory power as larger-scaled GCMgenerated data. This implies that grid-box-scale climate data (modeled or actual) contain valuable information of use, at the very least, for ecological analyses.
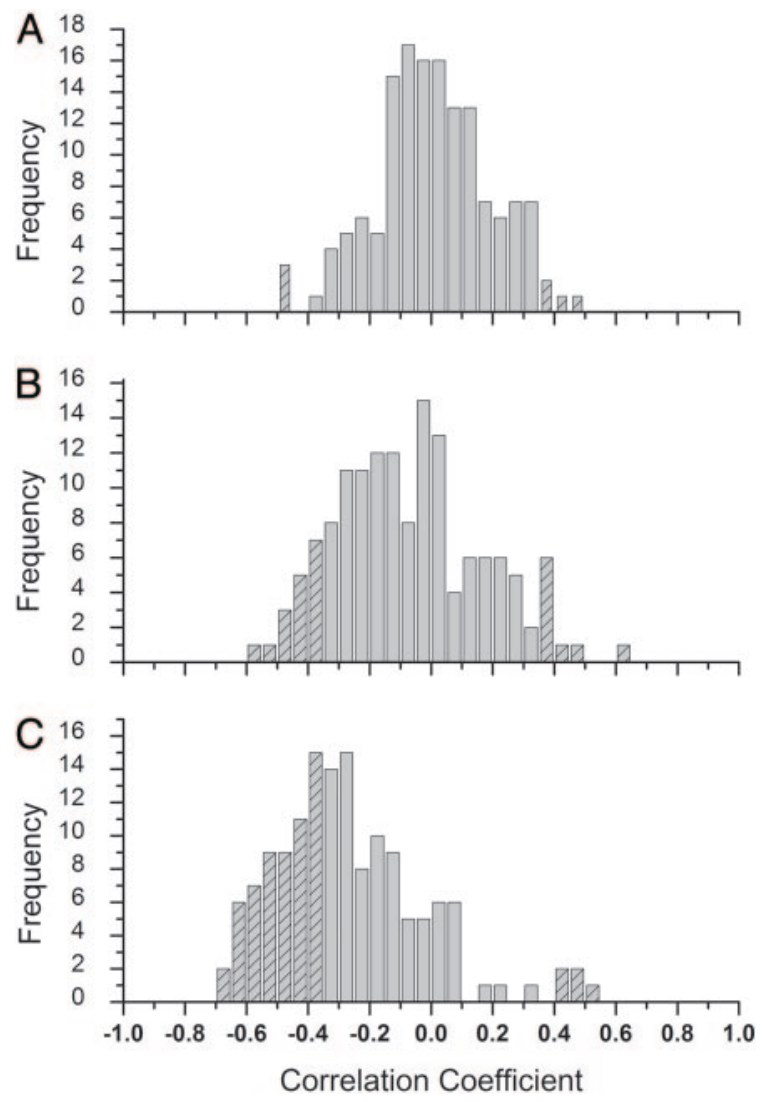

Fig. 2. Frequency of correlation coefficients calculated between species' phenological traits and modeled spring (March, April, and May) temperatures for all species showing phenological changes $(n=145)$ assuming NF $(A), \operatorname{AF}(B)$, or CF $(C)$. The striping indicates that all of the indicated correlation values are statistically significant $(P<0.1)$.

Monte Carlo Simulations. The means calculated with Monte Carlo simulations are similar to the statistical means described above. In all simulations, the mean of the correlation coefficients derived by using modeled temperatures resulting from NF is lower than the mean of the correlation coefficients between species' data and temperatures modeled with CF. Thus, our results above do not appear to be significantly skewed because of having several species reported within a single grid cell.

Frequency Distribution of the Correlation Coefficients. We examined the frequency distributions of the correlation coefficients for all 145 species with each of the three forcings at both the local and regional scales. Results for both spatial scales are, again, nearly identical, and thus only the local scale is plotted (Fig. 2). If the associations were random, we would expect the frequency of the species' correlation coefficients to be normally distributed around zero, roughly what we find when temperatures are modeled by using NF (Fig. $2 A$ ); the median correlation coefficient is 0.004 . Indeed, only 9 of $145(6 \%)$ species show a statistically significant association with naturally forced temperature model $(P<0.10)$. The frequency distribution of the correlation coefficients between species' data and temperatures modeled with only AF (Fig. $2 B$ ) produces a less random pattern than for the NF, with 28 of 145 species (19\%) showing statistically significant associations. The median correlation coefficient is -0.09 . Finally, the frequency distribution of correlation coefficients between species' data and temperatures modeled with $\mathrm{CF}$ (Fig. $2 C$ ) is strongly skewed to the left-a median correlation coefficient of -0.31 -because of the strongly neg- 
ative phenological response; 64 of 145 species (44\%) have statistically significant associations with $\mathrm{CF}$ modeled temperatures. All but five of these 64 species demonstrate negative associations.

\section{Conclusions}

Our analyses examine a type of data not previously used for climatic change attribution studies: shifting traits in the natural history of plants and animals. These data provide an independent proxy of the change in global temperature over time that is not plagued with disputes (regardless of the merits of the claims) over the reliability and validity of the instrumental record of temperature. The observed temporal changes in the phenological traits of plants and animals around the planet are more closely associated with HadCM3 temperatures modeled with $\mathrm{AF}$, either combined with $\mathrm{NF}$ or alone, than with modeled temperatures assuming only NF (Figs. 1 and 2). These results provide strong evidence of joint attribution (also called double attribution): Humans are contributing to changing regional temperatures, which in turn are associated with changes in wild species. Therefore, we conclude that human activities are highly likely to be contributing to the changes in regional surface temperatures, and these human-influenced temperature patterns are significantly associated with discernible changes in plant and animal phenological traits. Additionally, our results provide an independent validation test at both local (one grid box) and more regional (nine grid boxes) scales of a GCM driven by typically assumed AF and NF.

Despite careful caveats that most climate modelers warn should be applied to results obtained from GCMs at grid boxes

1. IPCC (2001) Climate Change 2001: The Science of Climate Change. Contribution of Working Group I to the Second Assessment Report of the Intergovernmental Panel on Climate Change (Cambridge Univ. Press, New York).

2. Stott, P., Tett, S., Jones, G., Allen, M., Mitchell, J. \& Jenkins, G. (2000) Science 290, 2133-2137.

3. Stott, P. (2003) Geophys. Res. Lett. 30, 1728.

4. Santer, B., Wehner, M., Wigley, T., Sausen, R., Meehl, G., Taylor, K., Ammann, C., Arblaster, J., Washington, W. M., Boyle, J., et al. (2003) Science 301, 479-483.

5. Mann, M., Ammann, C., Bradley, R., Briffa, K., Crowley, T., Jones, P., Oppenheimer, M., Osborn, T., Overpeck, J., Rutherford, S., et al. (2003) Eos 84, 256-258.

6. Root, T. L., Price, J., Hall, K., Schneider, S. H., Rosenzweig, C. \& Pounds, J. A. (2003) Nature 421, 57-60.

7. Root, T. L. \& Schneider, S. H. (2002) in Wildlife Responses to Climate Change: North American Case Studies, eds. Root, T. L. \& Schneider, S. H. (Island, Washington, DC), pp. 1-56.

8. Parmesan, C. \& Yohe, G. (2003) Nature 421, 37-42.

9. Gordon, C., Cooper, C., Senior, C., Banks, H., Gregory, J., Johns, T., Mitchell, J. \& Wood, R. (2000) Clim. Dyn. 16, 147-168.

10. Giorgi, F., Hewitson, B., Christensen, J., Hulme, M., Von Storch, H., Whetton, R., Jones, R., Mearns, L., Fu, C., Arritt, R., et al. (2001) in Climate Change 2001: The Scientific Basis (Cambridge Univ. Press, New York), pp. 583-638.

11. Gallo, K., Tarpley, J., McNab, A. \& Karl, T. (1995) Atmos. Res. 37, 37-43.

12. Santer, B., Wigley, T., Meehl, G., Wehner, M., Mears, C., Schabel, M., Wentz, F., Ammann, C., Arblaster, J., Bettge, T., et al. (2003) Science 300, 1280-1284.

13. Walther, G.-R., Post, E., Convey, P., Menzel, A., Parmesan, C., Beebee, T. J. C., Fromentin, J.-M., Hoegh-Guldberg, O. \& Bairlein, F. (2002) Nature 416, 389-395.

14. Thomas, C., Cameron, A., Green, R., Bakkenes, M., Beaumont, L., Collingham, Y., Erasmus, B., de Siqueira, M., Grainger, A., Hannah, L., et al. (2004) Nature 427, 145-148.

15. Abu-Asab, M. S., Peterson, P. M. \& Shetler, S. G. (2001) Biodiversity and Conservation 10, 597-612.

16. Ahas, R., Aasa, A., Menzel, A., Fedotova, V. \& Scheifinger, H. (2002) Int J. Clim. 22, 1727-1738.

17. Beaubien, E. G. \& Freeland, H. J. (2000) Int. J. Biometeorol. 44, 53-59.

18. Beebee, T. J. C. (1995) Nature 374, 219-220.

19. Bertram, D., Mackas, D. \& McKinnell, S. (2001) Prog. Oceanogr. 49, 283-307.

20. Bradley, N. L., Leopold, A. C., Ross, J. \& Huffaker, W. (1999) Proc. Natl. Acad. Sci. USA 96, 9701-9704.

21. Chuine, I., Cambon, G. \& Comtois, P. (2000) Glob. Change Biol. 6, 943-952. or small regional scales (10), the highly significant detection and attribution of HadCM3-GCM-produced anthropogenically forced climatic signals in the plant and animal records are strong validation that the model has discernible predictive ability at these relatively localized scales. At these scales, the HadCM3 GCM is simulating past temperature trends that are clearly detectable in responses of wild species. Both this confirmation of the sensitivity of species to temperature trends, and our detection of significant plant and animal correspondence with GCM results using AF alone or in conjunction with $\mathrm{NF}$ (and relatively weak correlations for NF alone), support the findings of previous studies $(2,3,6-8)$ using only meteorological instrumental observations of temperature. These studies claim detection and attribution of anthropogenic climatic changes and climatic impacts in observational data. We assert that all these studies taken together demonstrate that recent (at least for the latter few decades of the 20th century) climatic changes seen at both the local and nine-grid-box scales, and observed changes in wild species, are highly likely to be forced to a considerable degree by human emissions of greenhouse gases and aerosols.

We thank all of the lead authors of Chapter 5 of the IPCC Working Group 2 Third Assessment Report, particularly C. Rosenzweig, M. Apps, and C. Parmesan, for providing appropriate articles; S. Pimm, B. Santer, T. Wigley, D. Ackerley, S. Bilig, and D. G. MacMynowski for helpful suggestions and comments; C. Leopold, E. Losey, and J. A. Pounds for data; the Hadley Centre, specifically G. Jenkins and P. Stott, for providing the GCM data; K. Snyder and R. Hansen for data input; the Winslow Foundation for partial funding for D.PM., T.L.R., and S.H.S.; the U.S. Department of Energy Global Change Education Program for funding M.D.M.; and the U.K. Department of the Environment for funding HadCM3.

22. Crick, H., Dudley, C., Glue, D. \& Thomson, D. (1997) Nature 388, 526.

23. Defila, C. \& Clot, B. (2001) in "Fingerprints" of Climate Change: Adapted Behaviour and Shifting Species Ranges, eds. Walther, G.-R., Burga, C. \& Edwards, P. J. (Plenum, New York), pp. 113-123.

24. Emberlin, J., Mullins, J., Corden, J., Jones, S. \& Millington, W. (1999) Clin. Exp. Allergy 29, 347-356.

25. Huppop, O. \& Huppop, K. (2003) Proc. R. Soc. London Ser. B 270, 233-240.

26. Inouye, D. W., Barr, B., Armitage, K. B. \& Inouye, B. D. (2000) Proc. Natl. Acad. Sci. USA 97, 1630-1633.

27. Jarvinen, A. (1989) Ornis Fennica 66, 24-31.

28. Jenkins, D. \& Watson, A. (2000) Bird Study 47, 249-251.

29. Ludwichowski, I. (1997) Vogelwarte 39, 103-116.

30. MacInnes, C. D., Dunn, E. H., Rusch, D. H., Cooke, F. \& Cooch, F. G. (1990) Can. Field Naturalist 104, 295-297.

31. McCleery, R. H. \& Perrins, C. M. (1998) Nature 391, 30-31.

32. Penuelas, J., Filella, I. \& Comas, P. (2002) Glob. Change Biol. 8, 531-544.

33. Roetzer, T., Wittenzeller, M., Haeckel, H. \& Nekovar, J. (2000) Int. J. Biometeorol. 44, 60-66.

34. Roy, D. B. \& Sparks, T. H. (2000) Glob. Change Biol. 6, 407-416.

35. Schneigg, K., Pasinelli, G., Walters, J. \& Daniels, S. (2002) Proc. R. Soc. London Ser. B 269, 1153-1159.

36. Slater, F. M. (1999) Ibis 141, 497-499.

37. Spano, D. (1999) Int. J. Biometeorol. 42, 124-133.

38. Sparks, T. \& Braslavska, O. (2001) Int. J. Biometeorol. 45, 212-216.

39. Van Vliet, A. J. \& Schwartz, M. D. (2002) Int. J. Clim. 22, 1713-1714.

40. Visser, M. E., Vannoordwijk, A. J., Tinbergen, J. M. \& Lessells, C. M. (1998) Proc. R. Soc. London Ser. B 265, 1867-1870.

41. Winkel, W. \& Hudde, H. (1996) J. Fuer Ornithol. 137, 193-202.

42. Yoshino, M. \& Ono, H. P. (1996) in Climate Change and Plants in East Asia, eds. Omasa, K., Kai, K., Taoda, H., Uchijima, Z. \& Yoshino, M. (Springer, New York), pp. 93-107.

43. Zheng, J., Ge, Q. \& Hao, Z. (2002) Chin. Sci. Bull. 47, 1826-1829.

44. Trenberth, K. E. (1992) Climate System Modeling (Cambridge Univ. Press, Cambridge, U.K.).

45. Root, T. L. \& Schneider, S. H. (1995) Science 269, 334-341.

46. Zavaleta, E., Shaw, M., Chiariello, N., Thomas, B., Cleland, E., Field, C. \& Mooney, H. (2003) Ecol. Monogr. 73, 585-604.

47. Moss, R. H. \& Schneider, S. H. (2000) in Guidance Papers on the Cross Cutting Issues of the Third Assessment Report of the IPCC, eds. Pachauri, R., Taniguchi, T. \& Tanaka, K. (Intergovernmental Panel on Climate Change, Geneva), pp. 31-51; available from the Global Industrial and Social Progress Research Institute, www.gispri.or.jp. 